\title{
IDENTIFIYING CAUSES OF POWER REDUCTION IN PHOTOVOLTAIC SYSTEMS
}

\author{
S. Silvestre and A. Chouder \\ MNT - Electronic Engineering Department, Universitat Politècnica de Catalunya \\ C/ Jordi Girona 1-3, Campus Nord UPC, 08034 Barcelona, Spain
}

\begin{abstract}
A procedure for the identification of main causes of power reduction in PV systems, based on the continuous check of the real measured losses and his comparison to simulation results obtained for the same parameter, is presented in this work.
\end{abstract}

\section{INTRODUCTION}

The estimation of the energy generated by the PV systems is a widely boarded subject in literature [1-3]. However, when the production of different installed photovoltaic systems is evaluated, certain discrepancies have been found between the predictions of the models and the measures of the energy injected to the electrical network. An illustrative example of the performance of grid connected systems is the one given by the international energy agency PVPS Task2 [4], where it is reported from the analysis of 170 grid-connected PV systems, that the annual performance ratio, (PR), differs significantly from plant to plant and ranges between 0.25 and 0.9 with an average value of 0.66 .

In this work, we focus our research on the DC part of the PV system, as most inverters incorporate sufficient elements of protection to major operational problems that cause the reduction of output power. Many factors at the DC side, can cause reduced power output of a photovoltaic system, for example: wrong maximum power point tracking, thermal effects, mismatch of the PV modules due the non uniform distribution of irradiance and temperature, partial shadowing, wiring losses, aging, dirt accumulation, and losses caused by faulty operation such as faulty strings, faulty modules or short circuit of modules. The identification technique presented in this work allows establishing the likely causes of losses when there is a reduction in the power output of the PV system.

\section{SCOPE AND APPROACH}

In recent years we have been working on the development and validation of simulation models for PV systems, using tools such as PSpice [5] and Matlab\& Simulink [6-8]. We have developed a Simulink model to reproduce currentvoltage curves of solar cells and PV modules, by applying the classical one diode model, given by Eq. 1.

$$
I=I_{P H}-I_{o}\left[\exp \left(\frac{V+R_{s} I}{n V_{t}}\right)-1\right]-\left(\frac{V+R_{s} I}{R_{s h}}\right)
$$

Where: I and V, are the output PV cell current and voltage, Rs is the series resistance, Rsh is the shunt resistance, $\mathrm{IPH}$ is the photo-generated current, lo the saturation current, $\mathrm{n}$ the ideality factor, and $\mathrm{Vt}$ the thermal voltage.

Monitored data sets have been obtained from an operational grid connected photovoltaic system of $3.2 \mathrm{Kwp}$ organized on two strings, having fifteen Isofoton 106/12 modules for string. First we measured the current/voltage characteristic of a single module randomly chosen and after we measured the whole array current voltage characteristic. A nonlinear regression method was applied to both data sets in order to obtain the set of parameters that better approaches the real behaviour of the PV generator [3]. The translation procedure to standard test conditions, described by Christian Bendel et al. [9] has been used to derive values at standard conditions, STC At this point the losses due to mismatch effects can be evaluated $[3,8]$.

Four performance parameters established by the International Energy Agency (IEA) Photovoltaic Power System Program and described in the IEC standard 61724 define the overall system performance with respect to the energy production [10], solar resources, rated power and overall effect of system losses. These performance parameters are namely the reference yield $(\mathrm{Yr})$, array yield (Ya), final yield (Yf) and finally the performance ratio (PR). We use some of these parameters to evaluate the losses present in the PV system. The normalized total inherent losses, L, can be calculated by the following expression, after calculation of the reference and array yields:

$$
L=Y_{r}\left(G, T_{C}\right)-Y_{a}\left(G, T_{C}\right)=\frac{H_{i}}{G_{r e f}}(G, T c)-\frac{E_{d c}}{P_{r e f}}(G, T c)
$$

Where : $\operatorname{Yr}(\mathrm{G}, \mathrm{Tc})$ and $\mathrm{Ya}(\mathrm{G}, \mathrm{Tc})$ are the reference and array yields respectively, at real working irradiance, $G$ and real module temperature $\mathrm{Tc}, \mathrm{Hi}$ is the total plane of array irradiation in $\mathrm{Wh} / \mathrm{m} 2$, Gref is the reference irradiance at STC $(1000 \mathrm{~W} / \mathrm{m} 2)$, Edc is the energy produced by $\mathrm{PV}$ array $(\mathrm{kWh})$, and Pref is the maximum power output of PV array (kWp).

These losses can be divided into two groups, one associated with thermal effects, ThL, and another comprising the rest of possible effects that cause loss of power, miscellaneous losses, ML, thus:

$$
L=T h L+M L
$$


Normalized thermal losses can give us the amount of power losses due the rise of temperature above $25^{\circ} \mathrm{C}$. The thermal losses, ThL, can be then determined by the following expression:

$$
T h L=Y_{a}\left(G, 25^{\circ} C\right)-Y_{a}\left(G, T_{c}\right)=\frac{E_{d c}}{P_{r e f}}\left(G, 25^{\circ} C\right)-\frac{E_{d c}}{P_{r e f}}(G, T c)
$$

Where: Ya_ $\left(\mathrm{G}, 25^{\circ} \mathrm{C}\right)$ is the normalised energy yield at real working irradiance and $25^{\circ} \mathrm{C}$ of temperature, The temperature losses will be positive when the effective module temperature exceeds $25^{\circ} \mathrm{C}$, otherwise the losses are negative.

The procedure for identifying causes of power losses is based on the continuous check of the real measured losses and his comparison to simulation results obtained for the same parameter. The losses are within the theoretical limits permitted if the following expression is satisfied:

$L($ simulated $)-b<L($ measured $)<L($ simulated $)+b$

Where the standard deviation, $b$, is calculated depending on the percentage of losses in the system that forces the start of the analysis.

Finally, to decide the most likely cause in the reduction of power, we need to compare the measured values of voltage and current output of the generator with the results obtained in the simulation for these parameters. Table 1 shows the conditions needed to identify each one of the most probably causes in output power reduction.

\begin{tabular}{|c|c|}
\hline $\begin{array}{c}\text { Reduction in Output power } \\
\text { detected: } \\
\begin{array}{c}L \text { (measured })<L \text { (simulated })-b \\
\text { or } \\
L \text { (measured })>L \text { (simulated })+b\end{array}\end{array}$ & $\begin{array}{l}\text { Cause of output power } \\
\text { reduction }\end{array}$ \\
\hline $\begin{array}{l}\text { Constant energy loss } \\
T L>M L \\
T L<M L \text { and } I \text { sim }>\text { Im } \\
T L<M L \text { and } V \operatorname{sim}>V m \\
T L<M L \text { and } I \operatorname{sim}>>\text { Im }\end{array}$ & $\begin{array}{l}\text { Thermal effects } \\
\text { Soiling } \\
\text { PV modules in Open } \\
\text { circuit Faulty String }\end{array}$ \\
\hline $\begin{array}{l}\text { Short time energy loss } \\
\mathrm{TL}>\mathrm{ML} \\
\mathrm{TL}<\mathrm{ML} \text { and } \mathrm{Isim}>\mathrm{Im} \\
\mathrm{TL}<\mathrm{ML} \text { and } \mathrm{Vsim}>\mathrm{Vm}\end{array}$ & $\begin{array}{l}\text { Thermal effects } \\
\text { Partial Shadowing } \\
\text { MPP tracking error }\end{array}$ \\
\hline
\end{tabular}

Table 1. Identification Algorithm

\section{RESULTS OBTAINED}

The following causes of power reduction have been successfully identified in our experiments: Thermal effects, partial shadowing, PV modules in open circuit and faulty String.

We show below results obtained in case of partia shadowing operation as example of the presented procedure. A comparison between the simulation results for the PV system output power and the monitored data show the apparition of important differences between both quantities for small periods of time (see Fig.1), forcing the measured losses to exceed the permitted limits (see Fig.2)

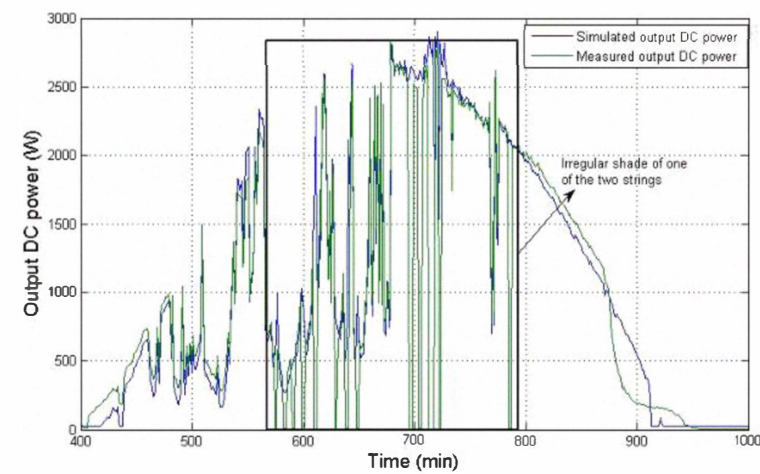

Figure 1 Simulated and Measured Output DC power.

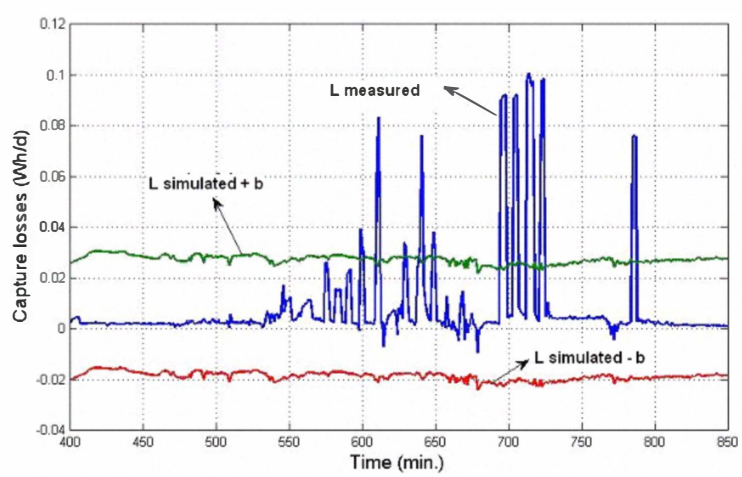

Figure 2 Measured losses.

Analyzing the evolution of the thermal losses, $\mathrm{TL}$, and the miscellaneous losses, ML, (see Fig. 3 and Fig.4), we can conclude that the output power reduction is not caused by thermal effects.

Finally, we observe more important differences, between simulation results and monitored data, for the output current than for the output voltage, (see Fig. 5), so that the identification procedure generates an error signal, (see Fig.6), which indicates the operation in partial shading of the PV system. 


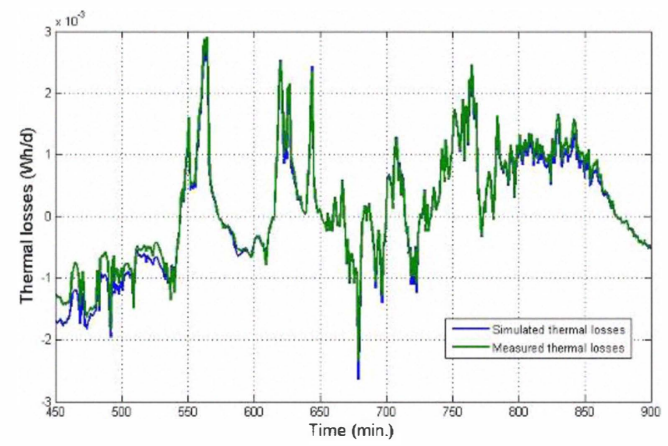

Figure 3 Thermal losses.

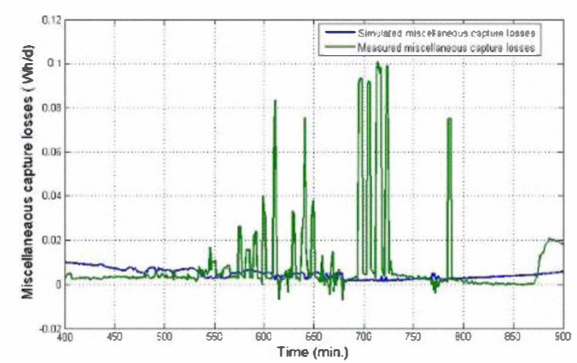

Figure 4 Miscellaneous losses.

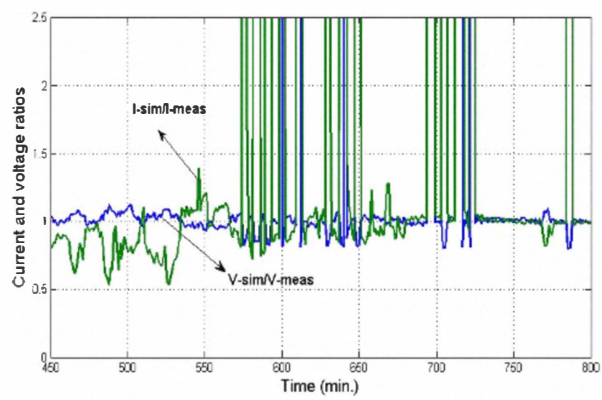

Figure 5 Simulation results and monitored I \&V.

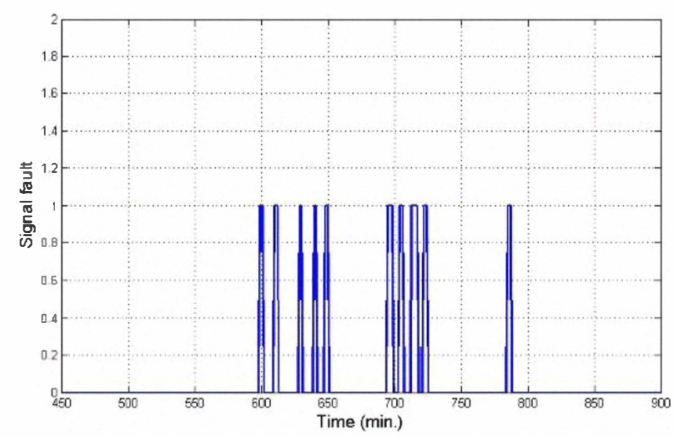

Figure 6 Error signal.

\section{CONCLUSIONS}

A procedure of identification of main causes of power reduction in PV systems has been developed.

This procedure is based on the continuous check of the real measured losses and his comparison to simulation results obtained for the same parameter.

Some typical causes of power reduction have been successfully identified in our experiments.

\section{REFERENCES}

[1] O.Perpiñan, E.Lorenzo and M.A. Castro, " On the calculation of energy produced by a PV Grid-connected system ", Progress in photovoltaics : Research and applications 15, 2007, pp.265-274.M.

[2] A. Hunter Fanney, Mark W. Davis, Brian P. Dougherty David L. King, William E. Boyson, and Jay A. Kratochvil D. I. King, J. A. Kratochvil, "Comparison of Photovoltaic Module Performance Measurements", J. Sol. Energy Eng. Vol. 128 (2), 2006, pp.152-160.

[3] A. Chouder and S. Silvestre, "Analysis Model of Mismatch Power Losses in PV systems", J. Sol. Energy Eng. 131 (2), 2009, pp.24504-1/24504-5.

[4] Report IEA-PVPS T-7 08:2002 "Reliability Study of grid connected PV systems: Field experience -and recommended design practice", Edited by Hermann Laukamp, Fraunhofer Institut für Solare Energiesysteme, 2002.

[5] L.Castañer and S. Silvestre, " Modelling Photovoltaic Systems using Pspice", Wiley 2002.

[6] S.Silvestre, D.Guasch, P.Ortega and R.Calatayud, "Photovoltaic Systems Modelling using Matlab and Simulink". 19th European Photovoltaic Solar Energy Conference, 2004, pp.2207-2210.

[7] S.Silvestre and A.Chouder, "Effects of shadowing on photovoltaic module performance". Progress in Photovoltaics: Research and applications 16, 2008, pp.141-149.

[8] S.Silvestre and A.Chouder, " Analysis of Power losses in PV Systems", 23rd European Photovoltaic Solar Energy Conference, 2008, pp.2805-2807

[9] Bendel, A. Wagner, 'Photovoltaic measurement relevant to the energy yield', WCPEC-3 World Conference on Photovoltaic Energy Conversion, 2003, pp. 2227-2230.

[10] International Electrotechnical Commission "Photovoltaic system performance Monitoring - Guidelines for measurement, data exchange and analysis", International Standard IEC 61724, Switzerland, 1998. 